Preprints of the

Max Planck Institute for

Research on Collective Goods

Bonn 2017/12

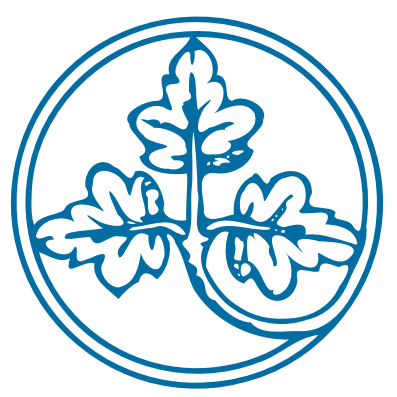

Volunteering under

Population Uncertainty

Adrian Hillenbrand

Fabian Winter

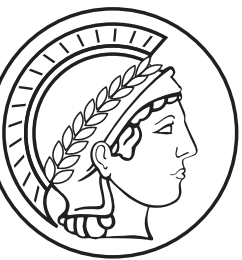




\section{Volunteering under Population Uncertainty}

Adrian Hillenbrand / Fabian Winter

July 2017 


\title{
Volunteering under Population Uncertainty
}

\author{
June 8, 2017
}

\author{
Adrian Hillenbrand 10 Fabian Winter ${ }^{2}$
}

\begin{abstract}
There is ample evidence that the number of players can have an important impact on the cooperation and coordination behavior of people facing social dilemmas. With extremely few exceptions, the literature on cooperation assumes common knowledge about who is a player and how many players are involved in a certain situation. In this paper, we argue that this assumption is overly restrictive, and not even very common in realworld cooperation problems. We show theoretically and experimentally that uncertainty about the number of players in a Volunteer's Dilemma increases cooperation compared to a situation with a certain number of players. We identify additional behavioral mechanisms amplifying and impairing the effect.
\end{abstract}

\section{Introduction}

Modern societies become increasingly dispersed, and networks of social interaction that are commonly taken for granted are constantly replaced by more anonymous and short-lived social encounters. Even though those now diminishing close-knit groups have been identified as the nucleus of cooperative environments (Coleman, 1994, Putnam, 1995), the prevalence of cooperative behavior in modern societies is surprisingly high. People take care of refugees after humanitarian crises and natural disasters. Programmers provide others with open source software. Interested writers publish articles on Wikipedia, and activists take part in risky political campaigns. Even more surprising these outbursts of collective action often happen in fairly unstructured, spontaneous, and rapidly changing environments. Very naturally, individual information about personal costs and benefits, ties between actors, or the dimensions of problems entailed in the system is limited in those grassroot endeavors. We will refer to this multifaceted and rather blurred perception of the environment as environmental uncertainty.

Perhaps most importantly, we often have no or only partial information about how many other individuals are willing and able to engage. While we

\footnotetext{
${ }^{1}$ Max Planck Institute for Research on Collective Goods; Bonn Graduate School of Economics, University of Bonn. email hillenbrand@coll.mpg.de

${ }^{2}$ Max Planck Institute for Research on Collective Goods, Kurt-Schumacher-Str. 10, D53113 Bonn, Germany. email winter@coll.mpg.de We acknowledge financial support from the Max-Planck Society.
} 
may have an intuition about the number of other potential "volunteers", the exact number is usually unknown. This population uncertainty, which is a particular flavor of environmental uncertainty, has profound consequences for the nature of strategic interaction. In his seminal theoretical contribution to the understanding of population uncertainty, Myerson (1998) shows that assuming common knowledge about group sizes is by no means an innocent assumption (see also Myerson, 2000): relaxing this assumption has profound consequences for predicted behavior. Myerson (1998, 2000) develops the general class of Poisson games to study population uncertainty in large groups. This class of games has received considerable attention in political science, where it is used to model voter decisions when the number of voters is unknown (Nunez, 2010) or to model macro-economic outcomes, e.g., when the number of innovators is unknown (Makris, 2008; Milchtaich, 2004) ? $^{3}$ While population uncertainty has been studied in many contexts, the literature on cooperation is surprisingly mute on this issue. With very few exeptions, it assumes common knowledge about who is a player and how many players are involved in a certain situation.

The goal of this paper is therefore to analyze the effect of population uncertainty on cooperation, both theoretically and experimentally.

We introduce population uncertainty to the Volunteer's Dilemma (Diekmann, 1985), a well-known coordinate-to-cooperate game. In the Volunteer's Dilemma, a group of people can enjoy the benefits of cooperation if at least one group member volunteers to provide a public good. Providing the good, however, is associated with an indivisible cost, which is smaller than the gains every member of the group receives. Effects of different (certain) group sizes are well understood in the Volunteer's Dilemma (e.g., Franzen, 1995; Goeree et al. 2017), which makes it particularly suitable for the study of population uncertainty.

In our experiment, we compare volunteering behavior under a certain group size (CERTAIN) with volunteering behavior under uncertain group size where the mean of the group size is identical to the certain group size. We consider two uncertainty treatments where we vary the variance of the distribution of possible groups sizes. Further, we vary the costs of volunteering in order to study interaction effects between group size uncertainty and incentives.

Our game-theoretical model of these coordinate-to-cooperate situations predicts a higher cooperation rate under population uncertainty (see Section 2). However, population uncertainty may have additional psychological effects, which would have consequences for the direction of the effect. Kerr (1989) finds that perceived self-efficacy is decreasing in larger groups, which then leads to lower levels of cooperation in social dilemmas. Since population uncertainty might lead to a downward biased perception of the population size, this is likely to mitigate cooperation in some situations.

Consequently, the perception of the probability of oneself "making a difference" or being "critical" (Rapoport, 1987) is paramount to understanding

\footnotetext{
${ }^{3}$ Population uncertainty is studied more thoroughly in other contexts. In auctions (e.g., see Harstad et al. 1990 population uncertainty is shown to increase bids by and large, even though there are situations where this is reversed. This increase can at least in part be traced back to individual risk preferences (e.g., Haviv and Milchtaich 2012). Moreover, population uncertainty influences equilibrium spending in contests theoretically and experimentally (Lim and Matros 2009 Boosey et al. 2016). Further, even very well known economic results like the optimal pricing behavior in a Bertrand competition change with population uncertainty (Ritzberger 2009).
} 
cooperation and coordination under population uncertainty. We have good reasons to believe that in fact the perceived and not the objective criticality plays the decisive role to explain coordination and cooperation under population uncertainty (Chen et al., 1996).

We model perceived criticality as a direct consequence of pessimistic beliefs about objective probabilities. ${ }^{4}$ We thus go beyond the work of Au et al. (1998) and $\mathrm{Au}(2004)$, who provide suggestive evidence that population uncertainty has a negative effect on perceived criticality, but do not model the perceived criticality as a direct consequence of pessimism. Their prediction is experimentally corroborated by $\mathrm{Au}(2004)$, who shows that cooperation rates are indeed lower in a sequential threshold public-goods game with an uncertain group size. In contrast, our model predicts higher cooperation rates under population uncertainty. However, the fundamental difference between their setup and ours lies in the fact that in their case, successful cooperation requires more than one person.

The evidence for public-goods and common-pool resource games is less conclusive. Cooperation in linear public-goods experiments decreases under population uncertainty $(\mathrm{Kim}, 2016)$, but is not affected in the non-linear counterpart (Ioannou and Makris, 2015). In contrast to these findings, the exploitation of a common-pool resource decreases under population uncertainty (Au and Ngai, 2003), which may in part be explained by a convergence of diverse sharing norms to the equal division rule (Kwaadsteniet et al. 2008).

Our results show that population uncertainty indeed fosters cooperation (see Section 4). This contrasts with many findings on the more general topic of environmental uncertainty, where uncertainty usually leads to a reduction of cooperation levels (e.g. Rapoport et al., 1992, Van Dijk et al., 2004). Further, we find an interesting effect suggesting that many subjects are only willing to contribute if others also do, even though one cooperator is sufficient and efficient. Finally, we find evidence that population uncertainty shifts actions away from self-regarding motives to pro-social motives and that population uncertainty shifts the normative perspective of what is appropriate to do.

\section{Theory}

\subsection{The Volunteer's Dilemma}

The Volunteer's Dilemma (VOD) is an N-player coordination problem introduced by Diekmann (1985). The usual cover story goes that $N$ players, who all know of each other, face a problem in which one person has to cooperate (volunteer) to do something at some cost $c>0$ (e.g., bring a corkscrew to a barbecue in the park), such that everyone can enjoy some benefits $b>c$ (e.g., a nice glass of Chardonnay on a mild summer evening). The VOD thus constitutes a coordination problem in which everyone would be willing to cooperate if no one else cooperates (in the end it is not too much trouble to search for the corkscrew). However, everyone would prefer someone else to cooperate.

${ }^{4}$ Mansour et al. (2006) provides evidence for pessimistic beliefs in simple coin toss experiments. $\mathrm{Au}(2004)$ also shows that some subjects abstained from investing in a threshold public good out of fear that the group size would be too small. 
The payoffs of the decision makers in the VOD depend on whether they cooperate or defect and on the decision of the $N-1$ other subjects.

\begin{tabular}{r|ccccc} 
& \multicolumn{4}{c}{ Number of other cooperators } \\
own choice & 0 & 1 & 2 & $\ldots$ & $\mathrm{N}-1$ \\
\hline cooperate & $b-c$ & $b-c$ & $b-c$ & $\ldots$ & $b-c$ \\
defect & 0 & $b$ & $b$ & $\ldots$ & $b$
\end{tabular}

Table 1: Payoffs in the Volunteer's Dilemma where $b>c>0$

In the standard form with $N$ players, the VOD has $N+1$ Nash equilibria: $N$ equilibria in pure strategies where only one player cooperates and one in mixed strategies. The pure strategy equilibria are obviously hard to coordinate on in a fully symmetric setup without communication. The mixed strategy Nash equilibrium cooperation is feasible but inefficient 5 The symmetric mixed strategy Nash equilibrium (MSNE) $p^{*}$ (where $\mathrm{p}$ is the probability to cooperate) is given by:

$$
p^{*}=1-\left(\frac{c}{b}\right)^{\frac{1}{N-1}} .
$$

It is easy to see that $p^{*}$ is decreasing in $N$. How does the MSNE change if we introduce population uncertainty? We are not aware of any studies manipulating population uncertainty in a volunteer's dilemma. However, Weesie (1994) proposes a game theoretical model with incomplete information about the costs and benefits of other players in the VOD. This model could be extended to the VOD with population uncertainty if one allows benefits to be lower than the costs. In contrast, in our theoretical model, we focus on population uncertainty in the actual number of players in the group. That is, costs and benefits are common knowledge and constant across players.

\subsection{The Volunteer's Dilemma under Population Uncer- tainty}

We extend the analysis of the game by allowing the number of players to be stochastic. More precisely, players make their decision without knowing the actual group size. The distribution of the number of players $n$ is common knowledge. $n$ is drawn from a discrete probability distribution $h$ which can be defined as a vector $(h(1), \ldots, h(\bar{N})$ with $h(n)$ being the probability of having $n$ players in the group and $\bar{N}$ being the highest possible number of players (with $\bar{N}$ being arbitrarily large).

We are interested in the effect of population uncertainty on behavior. There are no asymmetric equilibria as in the standard VOD. The reason is that there is some positive probability that the designated volunteer is just not present in the game (will not come to the barbecue). Thus, we focus on symmetric MSNE.

The symmetric MSNE cooperation rate $p^{*}$ is given as the solution to the following equation:

$$
\frac{c}{b}=\sum_{n=1}^{\bar{N}} h(n)\left(1-p^{*}\right)^{n-1} .
$$

\footnotetext{
${ }^{5}$ See Goeree et al. $(2017)$ for a discussion on quantal response equilibria in the VOD.
} 
where $h$ describes the probability density of the distribution of the number of players with $h(n)$ being the probability of having $n$ players in the group (see Appendix A.1 for the full derivation).

We compare Nash equilibria under two distributions of group size where one distribution is more uncertain than the other. We use the notion of the meanpreserving spread. That is, let $f$ and $g$ be two distribution functions where $f$ is a mean-preserving spread of $g$, then we say $f$ is more uncertain than $g$.

Proposition 1 (Volunteering under population uncertainty): In the Volunteer's Dilemma, given fixed benefits and costs and given two distributions of the population size, $f$ and $g$, and let $f$ be a mean-preserving spread of $g$. The MSNE probability to cooperate is (weakly) higher under $f$ compared to $g$.

The proof of this proposition as well as a graph visualizing this proposition is provided in the Appendix.

As can be seen from the above equation (2), the cost-benefit ratio directly determines the equilibrium probability to cooperate. We provide a further proposition describing the interaction between population uncertainty and the costbenefit structure on the MSNE (the proof can also be found in the appendix). With

Proposition 2 (Incentives and population uncertainty): In the Volunteer's Dilemma, given two distributions of the population, $f$ and $g$ : If $f$ is a mean-preserving spread of $g$ and $f(1)>\frac{c}{b}$, then there exists some $\left(\frac{\hat{c}}{b}\right)$ s.t. the difference $p_{f}^{*}\left(\frac{c}{b}\right)-p_{g}^{*}\left(\frac{c}{b}\right)$ is decreasing in $\frac{c}{b}$ for $\frac{c}{b}>\left(\frac{\hat{c}}{b}\right)$ and increasing in $\frac{c}{b}$ for $\frac{c}{b}<\left(\frac{\hat{c}}{b}\right)$.

\subsection{Hypotheses}

In order to test our propositions empirically, we will focus on a subgroup of distribution functions and provide comparative statics for the values chosen in our experiment. In particular, we analyze a situation where the distribution of the number of players is given by a low, high, and median point, and each of the possibilities has the same probability. That is, $h\left(N_{c}-s\right)=\frac{1}{3}, h\left(N_{c}\right)=\frac{1}{3}$, $h\left(N_{c}+s\right)=\frac{1}{3}$, and $h(n)=0$ for all other $n$ where $s$ determines the spread of the distribution. The following graphs show the numerical predictions for different cost-benefit ratios for the two spreads that we consider in this experiment $(s=1$, $\left.s=2, N_{c}=3\right)$, as well as for the conditions where the number of players is certain $\left(s=0, N_{c}=3\right)$.

In this setup, we are able to test three hypotheses based on the two propositions. First, we test the general reaction to a change in volunteering cost, i.e., the cost-benefit ratio which is independent of whether the population size is certain or uncertain.

Hypothesis 1 The cooperation rate is decreasing in $c / b$.

In our experiment, we increase the spread of the distribution and keep the mean constant. Thus, using proposition 1, we arrive at the following hypothesis:

Hypothesis 2 An increase in the uncertainty of the group size leads to an increase in the cooperation rate. 
Finally, we expect an interaction effect between population uncertainty and the cost-benefit ratio, as is shown in proposition 2 . In the setup that we chose, the critical ratio $\left(\frac{\hat{c}}{b}\right)$ is actually very low and we will focus on conditions where the cost-benefit ratio is always higher than this critical value (see e.g., Figure 1). Reformulating proposition 2 for our setup and for all cases where we predict no ceiling effects:

Hypothesis $\mathbf{3}$ There is a positive interaction effect between uncertainty and a decrease in the cost-benefit ratio on the cooperation rate.

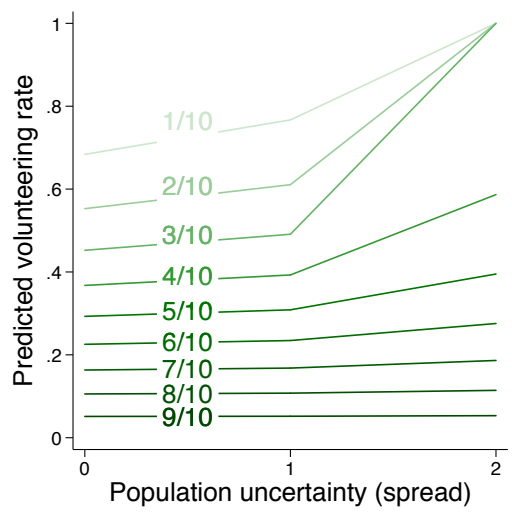

Figure 1: Predicted cooperation rates for different cost/benefit ratios and levels of population uncertainty. The fractions labeling the lines display the cost/benefit ratio.

\subsection{Criticality}

There are many reasonable arguments why deviations from the Nash equilibrium might occur. We focus on one key behavioral mechanism based on the literature. Perceived criticality, in contrast to actual criticality, is seen as a driving factor of behavior in setups with environmental uncertainty (Au et al. 1998). In contrast to the literature, we develop perceived criticality implicitly as a consequence of a biased perception of the environment. We assume that decision makers have pessimistic beliefs about the number of players (see $\mathrm{Au}$ (2004) and Mansour et al. (2006)), which is modeled by an increased probability weight on the lower end of the distribution function. Importantly, from this it follows that perceived criticality only has an influence under population uncertainty. Assuming pessimistic, but common, beliefs about the group size, we arrive at the following hypothesis (the theoretical derivation can be found in the Appendix).

Hypothesis 4 Perceived criticality is higher than actual criticality under population uncertainty, but not if the population size is certain.

Then, the impact on the predicted cooperation rate is as follows.

Hypothesis 5 Observed volunteering rates are higher than predicted by the MSNE, but only under population uncertainty. 


\section{Experimental Design}

Subjects in our experiment play a one-shot Volunteer's Dilemma with population uncertainty, as described above ${ }^{6}$ In our Volunteer's Dilemma setting, subjects simultaneously decide about whether they want to cooperate (volunteer) or defect (not volunteer). As long as at least one subject cooperates, every subject in the group receives a benefit $(b=10 €)$ and if no one cooperates, each subject receives $0 €$. Each cooperator carries a cost $c$, which is one of our treatment variables. The instructions framed the experiments as a decision about contributing to a project. The full instructions can be found in Appendix A.4. Subjects received a show-up fee of $4 €$.

We use a $3 \times 2$ factorial design where we vary the distribution of the group size (CERTAIN, LOW UNCERTAINTY, HIGH UNCERTAINTY) and the cost-benefit ratio of cooperation (LOW, HIGH).

In order to make meaningful comparisons and to have enough power to detect differences, we focus on small group sizes where, according to the theory, the effect should be more prominent. Further, we want to test whether the extent of the population uncertainty (i.e., the spread of the distribution) plays a role.

Thus, in the CERTAIN conditions, subjects play in a group of 3 and learn this before they make their decision. In the LOW UNCERTAINTY condition, subjects know that the group size is either 2,3 , or 4 , each with equal probability, but they learn the actual group size only after they make their decision. That is, they decide under population uncertainty. In the HIGH UNCERTAINTY condition the group size is either 1,3 , or 5 , each with equal probability.

Further, the theory predicts a stronger reaction to incentives under population uncertainty. To test this, we keep the benefits constant, but compare two cost conditions. For this we choose two cost-benefit values for which we expect a clear effect of population uncertainty and where the interaction effect should be sizeable, but at the same time we avoid ceiling effects as described by the condition in Proposition 2. Consequently, in the LOW COST treatment we set $c=4$, and in the HIGH COST treatment, we set $c=5$ (compare figure 1 ).

Table 2 shows the experimental treatments together with the mixed Nash equilibrium predictions for these treatments and shows that the expected differences are indeed sizeable.

The procedure for creating the groups of different sizes in the treatments with population uncertainty is critical. For the LOW UNCERTAINTY treatment, 24 subjects are invited to a session at the same time. Then, the group size is randomly determined $(2,3$, or 4$)$, and then all the subjects in the session are evenly distributed into groups of the randomly selected size. Subjects learn about the selected group size only after making their decision. For the HIGH UNCERTAINTY treatment, 15 subjects participate in each session and the procedure is identical to the procedure in the LOW UNCERTAINTY condition, but now with group sizes of 1,3 , or 5 subjects.

Before starting the experiment, the participants answered a set of 8 questions

\footnotetext{
${ }^{6}$ Playing repeatedly would give subjects a better chance at converging to the equilibrium prediction. Depending on the feedback after each round, repeated play might be highly complex. Choices might depend not only on past actions of others, but also on the draw of the group size. While this might lead to interesting dynamics, this is beyond the scope of this paper. The one-shot experiment gives us the cleanest data, given that we are focusing on the effect of population uncertainty.
} 


\begin{tabular}{lccc} 
& $\begin{array}{c}\text { predicted } \\
\text { volunteering rate }\end{array}$ & $N$ & avg. earnings \\
\hline low costs & & & \\
CERTAIN & .36 & 72 & $11.3 €$ \\
LOW UNCERTAINTY & .39 & 72 & $12.0 €$ \\
HIGH UNCERTAINTY & .58 & 75 & $9.9 €$ \\
high costs & & & \\
CERTAIN & .29 & 72 & $10.4 €$ \\
LOW UNCERTAINTY & .31 & 72 & $9.3 €$ \\
HIGH UNCERTAINTY & .39 & 75 & $9.5 €$ \\
\hline
\end{tabular}

Table 2: Treatments and symmetric MSNE predictions. Earnings include earnings from the experiment, show-up fee, and earnings from the risk-elicitation task.

about the rules of the game. Each of theses questions were answered correctly at the first attempt with only very few exceptions.

\subsection{Main measures}

Volunteering Choice Our main dependent variable will be the rate of cooperation. In order to obtain clearer insights into the strategic behavior of subjects and to increase statistical power, we provide subjects with a randomization device similar to Shachat (2002). Subjects choose the probability with which they want to cooperate by choosing the number of blue balls in a virtual urn with 100 balls. Afterwards, one of the 100 balls is chosen randomly and determines the choice of the subject, i.e., the subject cooperates if a blue ball is chosen. This allows us to determine whether decisions are the result of a mixed or pure strategy and also simplifies the elicitation of some of the further measures.7

Perceived Criticality The measure of perceived criticality was elicited after the volunteering choice. We asked subjects to imagine 100 identical situations and to state the number of times that they believe no one else in their group would cooperate. We chose not to incentivize this task, which would have required extensive explanation and some simulation during the experiment. Moreover, non-incentivized belief-elicitation tasks have recently been shown to be no worse or even better than their incentivized counterparts (Bellemare et al. 2012 ).

\subsection{Additional measures}

Since behavior under population uncertainty is not well understood, we use further measures that will improve our understanding of behavior in these situations and uncover underlying motives. These measures are not incentivized

\footnotetext{
${ }^{7}$ This method has the advantage that we can directly elicit individual mixed strategies instead of only obtaining treatment averages (Shachat, 2002). Importantly, our results seem to be robust qualitatively to the choice method. The corresponding data from a pilot study allowing only binary choices are available from the authors on request.
} 
(apart from the risk preference task) in order to simplify the experiment and prevent hedging possibilities between the main choice and, e.g., the belief task.

First Order Action Beliefs To measure first order action beliefs, we asked the subjects to state the share of other players who volunteer with a probability of $0-10 \%, 10-20 \%$, and so on. We designed a histogram-based measure, where the participants would move bars in a histogram up and down (see Appendix A.3.6 for a screenshot of the task). This gave them a visual representation of their beliefs. Just like the criticality measure, this measure was not incentivized.

Normative beliefs We measure normative beliefs by asking subjects what they think would be the appropriate probability to cooperate (i.e., the number of blue balls to put in the urn).

Risk Preferences Risk preferences where elicited with the Bomb Risk Ellicitation Task (Crosetto and Filippin, 2013). Subjects could earn up to $3.15 €$ in this incentivized measure ${ }^{8}$ Actual earnings from this task were between $0 €$ and $2.50 €$.

Underlying Motives Our final measure was a self-stated questionnaire comprised of 8 items. These items asked for potential underlying motives on a 7-point Likert scale. See Table 4 in the Appendix for the exact wording of the items.

\subsection{Participants}

Subjects were recruited using hroot (Bock et al. 2014). The experiment was conducted at the BonnEconLab at the University of Bonn and implemented in oTree (Chen et al. 2016). In total, 438 (75 in each of the HIGH UNCERTAINTY treatments and 72 in the other treatments, $\sim 59 \%$ female) subjects took part in the experiment from a wide range of different fields of study.

\section{Results}

We will structure this section according to the hypotheses we derived in the theory part. After that, we will present the results of an exploratory analysis of further underlying motives.

\subsection{Testing hypotheses}

Result 1 Lower costs of cooperation do not increase the probability to volunteer.

Hypothesis 1 predicts a negative relationship between the cost/benefit-ratio and cooperative choices. We do not find evidence in favor of this hypothesis. A Mann-Whitney test shows no systematic statistical differences between the cost conditions in the different uncertainty conditions (low vs. high costs: CERTAIN $p$ $=.71$; LOW UNCERTAINTY $\mathrm{p}=.63$; HIGH UNCERTAINTY $\mathrm{p}=.16$, see also Figure

\footnotetext{
${ }^{8}$ We use the pre-programmed tool by Holzmeister and Pfurtscheller $(2016)$ with $8 \times 8$ boxes and a payment of $0.05 €$ for each box.
} 
2). The difference is also small and statistically insignificant when pooling across all high-cost conditions with all low-cost conditions (.51 vs. .53, Mann-Whitney, $\mathrm{p}=.54)$. Since there is no statistical difference between the different cost conditions, we will from now on pool the data for those analyses which do not explicitly state the costs.

a

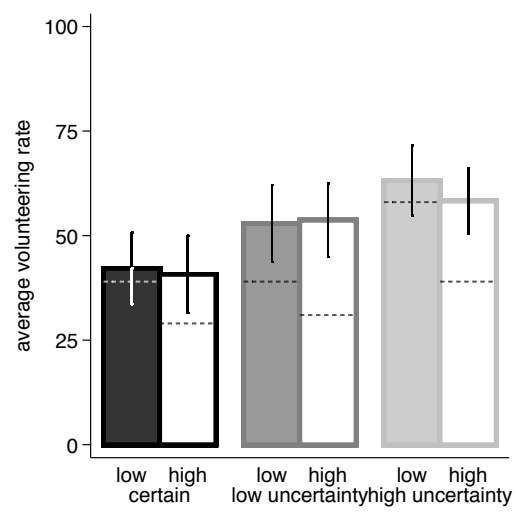

b

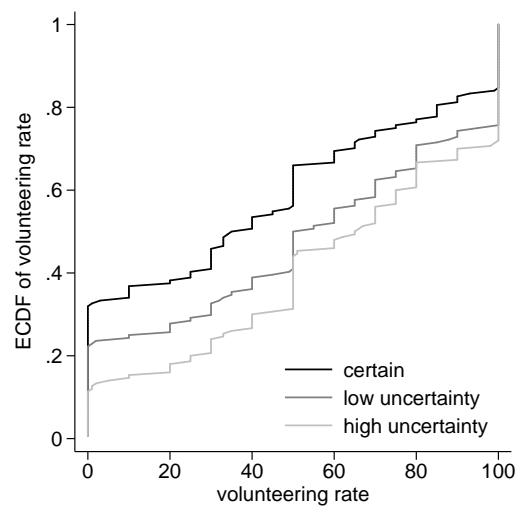

Figure 2: Average volunteering rates (a) and distribution of volunteering decisions (b). The error bars in (a) represent 95\%-confidence intervals.

\section{Result 2 Population uncertainty increases the probability to volunteer.}

Hypothesis 2 predicted higher cooperation rates under population uncertainty. This hypothesis is clearly confirmed by our data. Volunteering rates are higher in LOW UNCERTAINTY than in CERTAIN (.53 vs. .41, Mann-Whitney, $p<0.001$ ), and higher in HIGH UNCERTAINTY than in CERTAIN (.61 vs. .41, Mann-Whitney, $p<0.001)$. This result is also confirmed by the fractional logit model (1) in Table 3 , which is commonly used to model proportions in a regression framework (Papke and Wooldridge, 2008).

The difference between the two uncertain treatments is less pronounced. As predicted, the cooperation rates in HIGH UNCERTAINTY are higher than in LOW UNCERTAINTY. However, this difference is only weakly significant (.53 vs. .61, Mann-Whitney, $p=.0971)$. A Wald-test comparing the two uncertainty treatments in Table $3(2)$ leads to the same conclusion $(\mathrm{p}=.0829)$. This is in contrast to the predicted values, which led us to expect a small difference between CERTAIN and LOW UNCERTAINTY, but a big difference between LOW UNCERTAINTY and High UNCERTAINTY. It suggests that the mere existence of population uncertainty influences behaviour more than the degree of uncertainty.

Result 3 There is no interaction between the costs of cooperation and the degree of population uncertainty on cooperation behavior.

Hypothesis 3 predicts that people react more strongly to cost differences under higher population uncertainty. We therefore compare the differencesin-differences in high- and low-cost situations between the different uncertainty conditions. Our results, however, cannot confirm the predicted interaction effect 
Table 3: Fractional logit regression estimating the probability to volunteer.

\begin{tabular}{|c|c|c|c|c|}
\hline & (1) & $(2)$ & $(3)$ & (4) \\
\hline LOW UNCERTAINTY & $\begin{array}{c}0.118^{* *} \\
(2.65)\end{array}$ & $\begin{array}{c}0.107^{+} \\
(1.71)\end{array}$ & $\begin{array}{c}0.107^{+} \\
(1.73)\end{array}$ & $\begin{array}{c}0.101^{*} \\
(2.09)\end{array}$ \\
\hline HIGH UNCERTAINTY & $\begin{array}{l}0.193^{* * *} \\
\quad(4.53)\end{array}$ & $\begin{array}{c}0.210^{* * *} \\
(3.53)\end{array}$ & $\begin{array}{l}0.215^{* * *} \\
(3.69)\end{array}$ & $\begin{array}{c}0.139^{* *} \\
(3.07)\end{array}$ \\
\hline high costs & & $\begin{array}{c}-0.0143 \\
(-0.23)\end{array}$ & $\begin{array}{c}-0.00218 \\
(-0.03)\end{array}$ & $\begin{array}{c}0.0622 \\
(1.29)\end{array}$ \\
\hline LOW UNCERTAINTY $\times$ high costs & & $\begin{array}{c}0.0219 \\
(0.25)\end{array}$ & $\begin{array}{c}0.00431 \\
(0.05)\end{array}$ & $\begin{array}{c}-0.0842 \\
(-1.26)\end{array}$ \\
\hline HIGH UNCERTAINTY $\times$ high costs & & $\begin{array}{c}-0.0360 \\
(-0.42)\end{array}$ & $\begin{array}{c}-0.0573 \\
(-0.68)\end{array}$ & $\begin{array}{c}-0.0899 \\
(-1.45)\end{array}$ \\
\hline subj. criticality & & & $\begin{array}{c}-0.00238^{* *} \\
(-3.17)\end{array}$ & $\begin{array}{c}-0.00229^{* * *} \\
(-3.86)\end{array}$ \\
\hline pro-social & & & & $\begin{array}{c}0.203^{* * *} \\
(11.20)\end{array}$ \\
\hline pro-self & & & & $\begin{array}{c}-0.113^{* * *} \\
(-5.39)\end{array}$ \\
\hline $\begin{array}{l}\text { Observations } \\
\text { Pseudo } R^{2}\end{array}$ & $\begin{array}{c}438 \\
0.018\end{array}$ & $\begin{array}{c}438 \\
0.019\end{array}$ & $\begin{array}{c}438 \\
0.028\end{array}$ & $\begin{array}{c}438 \\
0.238\end{array}$ \\
\hline \multicolumn{5}{|l|}{$\begin{array}{l}z \text { statistics in parentheses } \\
+p<.10,{ }^{*} p<.05,{ }^{* *} p<.01,{ }^{* * *}\end{array}$} \\
\hline $\begin{array}{l}\text { Note Estimates show average margin } \\
\text { are dummy variables indicating the } \\
\text { a dummy taking " } 1 \text { " for the condition } \\
\text { stems from our measure of criticality } \\
\text { are the two factors obtained from the }\end{array}$ & $\begin{array}{l}\text { effects. LC } \\
\text { rrespondin } \\
\text { with a hiq } \\
\text { d takes val } \\
\text { xploratory }\end{array}$ & $\begin{array}{l}V \text { UNCERTA } \\
\text { uncertain } \\
\text { cost-bene } \\
\text { es from } 0\end{array}$ & $\begin{array}{l}\text { INTY and HIG } \\
\text { y conditions. } \\
\text { it ratio. Perc } \\
100 \text {. Pro-so } \\
\text { sis. }\end{array}$ & $\begin{array}{l}\text { UNCERTAINT } \\
\text { HIGH COSTS } \\
\text { eived criticalit } \\
\text { ial and Pro-se }\end{array}$ \\
\hline
\end{tabular}


of costs and population uncertainty. The two cost/uncertainty interaction terms in model (2) in Table 3 are not statistically different from zero, and a Wald-test shows that they are not different from each other either $(\mathrm{p}=.50)$.

Result 4 Volunteering rates are higher than suggested by the mixed Nash equilibrium.

The average volunteering rates are substantially higher than predicted by the mixed Nash equilibrium. The differences are statistically significant in all treatments apart from the low-cost CERTAIN and HIGH-UNCERTAINTY treatment. Table 5 in the Appendix shows the results of the corresponding t-tests. Pooling the cost-conditions, differences are significant at the $5 \%$ level for all degrees of uncertainty. In fact, volunteering decisions of individuals hardly ever match the predicted volunteering rates. In total, only 31 or $7.1 \%$ out of the 438 subjects played a strategy that is within $+/-5 \%$-points of the Nash prediction. One explanation is that approximately $45 \%$ of subjects play "pure strategies" (100 or 0 balls in the urn). Further, many subjects choose to volunteer with a $50 \%$ probability. There is also a clear difference between treatments in terms of pure strategies, as can be seen from the cdf in Figure 2 2 . In CERTAIN, about $32 \%$ of players defect ( 0 balls in the urn) compared to $22 \%$ in LOW UNCERTAINTY and $11 \%$ in HIGH UNCERTAINTY. On the other hand, $52 \%$ cooperate fully (100 balls in the urn) in CERTAIN, compared to $53 \%$ in LOW UNCERTAINTY and $60 \%$ in HIGH UNCERTAINTY.

\section{Criticality}

Based on our behavioral hypotheses, we expected a higher cooperation rate than predicted by perceived criticality to increase the cooperation rates beyond the point predictions of the mixed Nash equilibrium. While the above result is in line with Hypothesis 5 for the uncertain treatments, we also find higher cooperation for the CERTAIN treatment. Now we will show how this links to criticality. Our measure of perceived criticality asks subjects to state in how many of 100 identical situations they believe that no one else would volunteer. A higher value thus corresponds to a higher perceived criticality.

First, we look at the difference between perceived and objective criticality across treatments. We calculated the objective criticality as the probability that a subject is the only volunteer in a group 9 The confidence intervals for these proportions are calculated as Agresti-Coull intervals. Figure 3 shows that the objective criticality is the lowest in the LOW UNCERTAINTY treatment, where subjects were on average critical in about $26 \%$ of the cases. In the CERTAIN treatment they are critical in about $34.4 \%$, and in the high uncertainty treatment they are critical in $39.3 \%$, of the cases.

Result 5 Perceived criticality is higher than the objective criticality. There is no difference in perceived criticality between treatments.

\footnotetext{
${ }^{9}$ This probability is calculated as $\frac{1}{3} \sum_{r=1}^{3}\left(1-\left(1-\hat{v}^{t}\right)^{N_{r}-1}\right)$, where $\hat{v}^{t}$ depicts the estimated probability to volunteer in treatment $t$, and $N_{r}$ are the potential number of group members (e.g., 2,3 , and 4 in the Low unCERTAINTy treatment).
} 
a

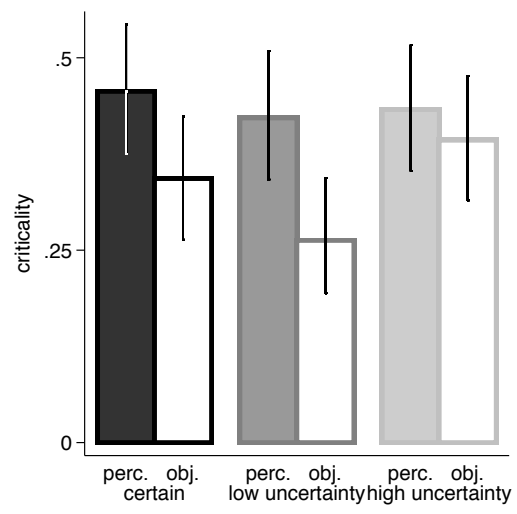

b

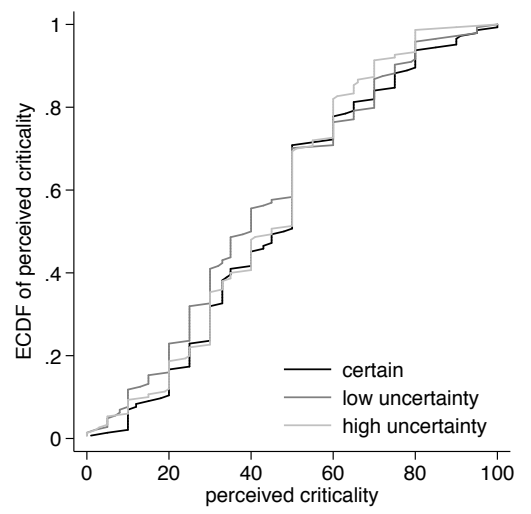

Figure 3: Perceived and objective criticality across treatments (a), and the distribution of perceived criticality (b). The perceived criticality was elicited by asking for the number of times no other participant would volunteer if the game was repeated 100 times. The objective criticality was calculated as a function of the observed volunteering rates.

Perceived criticality in all treatments is higher than the objective criticality ${ }^{10}$ This difference is statistically significant in the CERTAIN and the LOW UNCERTAINTY treatment, but not in the HIGH UNCERTAINTY treatment $(p<0.05$, see Table 7 in the Appendix). This is in contrast to Hypothesis 4 in that there is also a difference for the certain treatment and that we find no differences in perceived criticality between the treatments (all comparisons, Mann-Whitney, $p>0.1$ ).

This result is somehow confirmed when analyzing corresponding beliefs. Subjects expect others to be more cooperative in the uncertain treatments than in the certain treatments, though this difference is only statistically significant in the HIGH UNCERTAINTY case (LOW UNCERTAINTY vs. CERTAIN, 47.1 vs. 45.35, Mann-Whitney $p>0.1$, High UnCERTAinty vs. CERTAin, 50.75 vs. 45.35 , Mann-Whitney $p=0.0042$ ). Moreover, beliefs are more optimistic in HIGH UNCERTAINTY compared to Low UnCERTAINTY (Mann-Whitney, $p=0.07$ ).

Result 6 Perceived criticality has a negative effect on cooperation.

As can be seen from column (3) in Table 3 criticality influences behavior in an unexpected direction. The higher the perceived criticality, the less willing subjects are to cooperate.

This surprising finding is not simply an artifact of our criticality measure, as we can see from the independently measured first-order action beliefs. Beliefs match the distributions of choices quite well (see Figure 6 in the Appendix).

\footnotetext{
${ }^{10}$ In contrast to our assumptions, pessimism about the group size does not seem to influence the results. As a simple measure we ask subjects in the uncertain conditions to state their belief about the realized number of other players in their group. First, we do not find evidence for overall pessimism in these treatment with most people expecting the average group size. Second, there is no correlation between pessimistic beliefs and perceived criticality (Spearman, $\rho=0.0085, p>0.1$ ).
} 
Again, we find the same unexpected link between beliefs and choices. The more cooperative subjects believe others to be, the more likely they are to volunteer themselves. Column (5) in Table 3 in the Appendix shows the corresponding results of a fractional logit regression controlling for the treatment and the beliefs.

Overall this shows that indeed perceived criticality seems to play a crucial role for cooperation behavior, but in a different way than expected.

\subsection{Exploratory analysis}

So far, we have isolated some of the driving factors by looking at structural factors and beliefs and testing our hypothesis. The variance in the data that we can explain with theses factors is still far from 1 (see Table 3). We therefore also administered an 8-item questionnaire designed to measure plausible underlying motives. An exploratory factor component analysis reveals that 7 of the 8 items can be separated into two factors (see table 4 in the Appendix for the wording of the questionaire and details on the factor analysis). The additive index of these 7 items reaches satisfactory reliability as indicated by a Cronbach's $\alpha$ of 0.63 . The first factor can be broadly described as pro-social. It includes preferences for social efficiency, a feeling of duty, and the desire for the project to be successful. The second factor can be described as pro-self. It is a combination of the aversion to being taken advantage of and the preference that others take over the costs of providing the public good.

Including these self-stated factors in the regression sharply increases the adjusted $R^{2}$ and adds two strong predictors for behavior. While pro-sociality increases volunteering, self-serving preferences have the expected opposite effect (see column (4) in Table 3).

Result 7 Subjects state motives more in line with efficiency under population uncertainty and with self-serving motives when group size is certain.

Interestingly, these factors seem to be influenced by population uncertainty. This is surprising since these questions and motives suggest stemming from fixed preferences and should not be influenced by the treatment variation. Higher population uncertainty correlates positively with the pro-social factor (Spearman, $\rho=0.1327, p<0.0054)$, resulting in a negative correlation with the pro-self factor (Spearman, $\rho=-0.1380, p=0.0038$ ). We can therefore speculate that population uncertainty leads to a focus on social efficiency aspects of the decision and away from selfish aspects.

This finding is in line with our measure of normative beliefs. Subjects state that the appropriate probability to cooperate is higher in the uncertainty conditions compared to the condition with certain group size, although only significantly at the 10-percent level (LOW UNCERTAINTY vs. CERTAIN, 59.99 vs. 53.71, Mann-Whitney $p=0.0650$, HIGH UnCERTAINTy vs. CERTAin, 60.29 vs. 53.71, Mann-Whitney $p=0.0530)$. However, this result seems to be driven by the high-cost condition (see Table 8 in the Appendix). Subjects stating a higher value, i.e., subject who find a higher cooperation rate more appropriate also contribute more themselves (see Table 9 in the Appendix) 


\section{Discussion}

In this paper, we show theoretically and experimentally that population uncertainty influences behavior in a coordinate-to-cooperate dilemma. The theoretical result holds for all comparisons where one group size distribution is obtained by a mean-preserving spread from another distribution. In the experiment, we provide evidence in line with the theory for a range of the group size that is quite common in the literature. We find that higher population uncertainty leads to more cooperative choices. However, the degree of the uncertainty seems to play less of a role compared to the pure effect of the population being uncertain. However, cooperation in all our treatments is substantially higher than predicted by theory. There is no significant difference between our cost conditions, even though there is a clear difference in the predicted rates and in earlier studies. It is possible that more extreme cost differences might lead to stronger effects. We further elicited the participants' perceived criticality, that is, how likely they think it is their own choice that makes a difference. This perceived criticality is on average far above their objective criticality. However, in contrast to our hypothesis, we find no difference in perceived criticality between certain and the uncertain conditions.

Surprisingly, criticality influences choices in the reverse way than expected. Subjects who perceive themselves as more critical actually cooperate less. A similar effect can be found when looking at first-order action beliefs. The more strongly somebody believes in the cooperativeness of others, the more they cooperate themselves. The association between perceived criticality, beliefs, and choices is in line with the notion of conditional cooperation: subjects cooperate when they expect others to cooperate as well. However, the Volunteer's Dilemma is an extremely unexpected and puzzling example for this kind of behavior. Already one cooperator is sufficient and efficient to provide the collective good, and one would therefore expect a negative correlation between beliefs and choices.

We are confident that this behavior cannot be explained by mere confusion. We took great care in explaining the setup and subjects seemed to have no problem in answering the control questions. Moreover, the beliefs about behavior of the other players are surprisingly accurate, suggesting that behavior seems not to be driven by a fundamentally false perception of the environment.

One explanation for the puzzle might be normative behavior. Indeed we find that subjects' cooperation behavior correlates strongly with what they state as appropriate behavior. Thus, as long as the utility from adhering to the norm is high enough, subjects might prefer to cooperate if they think others cooperate as well (e.g., López-Pérez, 2008). Sources of this norm-following behavior might also be found in other social preferences, e.g., a high degree of inequity aversion.

An exploratory factor analysis of our questionnaire data reveals a further potential mechanism. The two factors obtained - roughly capturing pro-self and pro-social motives - are highly predictive of behavior. The explained variance tenfolds if these two variables are included in our regression.

Moreover, these factors as well as the stated appropriate behavior are influenced by population uncertainty. An increase in population uncertainty seems to shift behavioral factors away from pro-self and in the direction of pro-social motives. This is in line with studies on shifting norms based on cues in the environment (Lindenberg, 2012, Rutkowski et al. 1983) and would explain the 
observed treatment differences quite well. We would like to respect that these results are based on an exploratory analysis and require rigorous testing in other environments also which would be beyond the scope of this paper.

All the results are based on one-shot interaction. This gives us a clear test of population uncertainty and avoids reputation effects. However, in a repeated setting, one could study whether cooperation rates approach theoretical levels over time. Given the complexity of the repeated interaction in a situation where the number of players in each round is uncertain, this might lead to interesting dynamics. To study these dynamics is a natural next step.

Finally, our results are of importance not only for the Volunteer's Dilemma and other coordination games, but for the literature on cooperation in particular. We believe that the situation of population uncertainty is often the rule rather than the exception. This has rarely been acknowledged by the literature so far. If our results also hold in other contexts, cooperation is higher under population uncertainty, and this would mean that we usually underestimate cooperative behavior. The fact that the results in a relatively simple setting are already influenced by population uncertainty suggests that results in more complex situations might be influenced as well. Population uncertainty might not only lead to a simple level effect of cooperation, but could interact with taken-for-granted effects (e.g., the punishment in the public-goods game). Our results provide an important first step towards exploring these questions. 


\section{References}

Au, Wing Tung and Man Yuen Ngai, "Effects of Group Size Uncertainty and Protocol of Play in a Common Pool Resource Dilemma," Group Processes E Intergroup Relations, 2003, 6 (3), 265-283.

_ , Xiao-Ping Chen, and SS Komorita, "A probabilistic model of criticality in a sequential public good dilemma," Organizational Behavior and Human Decision Processes, 1998, 75 (3), 274-293.

Au, Winton, "Criticality and Environmental Uncertainty in Step-Level Public Goods Dilemmas," Group Dynamics: Theory, Research, and Practice, 2004, $8(1), 40-61$.

Bellemare, Charles, Luc Bissonnette, and Sabine Kröger, "Flexible approximation of subjective expectations using probability questions," Journal of Business 8 Economic Statistics, 2012, 30 (1), 125-131.

Bock, Olaf, Ingmar Baetge, and Andreas Nicklisch, "hroot: Hamburg registration and organization online tool," European Economic Review, 2014, $71,117-120$.

Boosey, Luke, Philip Brookins, and Dmitry Ryvkin, "Contests with group size uncertainty: Experimental evidence," 2016, (wp2016_07_01).

Chen, Daniel L., Martin Schonger, and Chris Wickens, "oTree - An Open-Source Platform for Laboratory, Online and Field Experiments"," working paper available at: www.otree.org/oTree.pdf., 2016.

Chen, Xiao-Ping, Wing Tung Au, and SS Komorita, "Sequential choice in a step-level public goods dilemma: The effects of criticality and uncertainty," Organizational Behavior and Human Decision Processes, 1996, 65 (1), 37-47.

Coleman, James S., Foundations of social theory, Harvard university press, 1994.

Crosetto, Paolo and Antonio Filippin, "The bomb risk elicitation task," Journal of Risk and Uncertainty, 2013, 47 (1), 31-65.

de Kwaadsteniet, Erik W., Eric van Dijk, Arjaan Wit, and David De Cremer, "How Many of Us Are There?': Group Size Uncertainty and Social Value Orientations in Common Resource Dilemmas," Group Processes 8 Intergroup Relations, 2008, 11 (3), 387-399.

Diekmann, Andreas, "Volunteer's dilemma," Journal of Conflict Resolution, 1985, pp. 605-610.

Dijk, Eric Van, Arjaan Wit, Henk Wilke, and David V Budescu, "What we know (and do not know) about the effects of uncertainty on behavior in social dilemmas," Contemporary psychological research on social dilemmas, 2004, pp. 315-331.

Franzen, Axel, "Group size and one-shot collective action," Rationality and Society, 1995, 7 (2), 183-200. 
Goeree, Jacob K, Charles A Holt, and Angela M Smith, "An experimental examination of the volunteer's dilemma," Games and Economic Behavior, 2017.

Harstad, Ronald M, John H Kagel, and Dan Levin, "Equilibrium bid functions for auctions with an uncertain number of bidders," Economics Letters, 1990, 33 (1), 35-40.

Haviv, Moshe and Igal Milchtaich, "Auctions with a random number of identical bidders," Economics Letters, 2012, 114 (2), 143-146.

Holzmeister, Felix and Armin Pfurtscheller, "oTree: The "bomb" risk elicitation task," Journal of Behavioral and Experimental Finance, 2016, 10, 105-108.

Ioannou, Christos A. and Miltiadis Makris, "An Experimental Study of Uncertainty in Coordination Games," Discussion Paper Series In Economics And Econometrics, September 2015, 1506.

Kerr, Norbert L, "Illusions of efficacy: The effects of group size on perceived efficacy in social dilemmas," Journal of experimental social psychology, 1989, 25 (4), 287-313.

Kim, Duk Gyoo, "Population Uncertainty in Voluntary Contributions of Public Goods," mimeo, 2016.

Lim, Wooyoung and Alexander Matros, "Contests with a stochastic number of players," Games and Economic Behavior, 2009, 67 (2), 584-597.

Lindenberg, S.M., How cues in the environment affect normative behavior, Wiley,

López-Pérez, Raúl, "Aversion to norm-breaking: A model," Games and Economic behavior, 2008, 64 (1), 237-267.

Makris, Miltiadis, "Complementarities and macroeconomics: Poisson games," Games and Economic Behavior, 2008, 62 (1), 180-189.

Mansour, Selima Ben, Elyès Jouini, and Clotilde Napp, "Is there a "pessimistic" bias in individual beliefs? Evidence from a simple survey," Theory and Decision, 2006, 61 (4), 345-362.

Milchtaich, Igal, "Random-player games," Games and Economic Behavior, 2004, 47 (2), 353-388.

Myerson, Roger B, "Population uncertainty and Poisson games," International Journal of Game Theory, 1998, 27 (3), 375-392.

_ , "Large poisson games," Journal of Economic Theory, 2000, 94 (1), 7-45.

Nunez, Matias, "Condorcet consistency of approval voting: a counter example in large Poisson games," Journal of Theoretical Politics, 2010, 22 (1), 64-84.

Osborne, Jason W and Anna B Costello, "Best practices in exploratory factor analysis: Four recommendations for getting the most from your analysis," Pan-Pacific Management Review, 2009, 12 (2), 131-146. 
Papke, Leslie E and Jeffrey M Wooldridge, "Panel data methods for fractional response variables with an application to test pass rates," Journal of Econometrics, 2008, 145 (1), 121-133.

Putnam, Robert D, "Bowling alone: America's declining social capital," Journal of democracy, 1995, 6 (1), 65-78.

Rapoport, Amnon, "Research paradigms and expected utility models for the provision of step-level public goods.," Psychological Review, 1987, 94 (1), 74.

_ , David V Budescu, Ramzi Suleiman, and Eythan Weg, "Social dilemmas with uniformly distributed resources.," in W. B. G. Liebrand, D. M. Messick, and H. A. M. Wilke, eds., International series in experimental social psychology., Elmsford, NY, US: Pergamon Press, 1992, pp. 43-57.

Ritzberger, Klaus, "Price competition with population uncertainty," Mathematical Social Sciences, 2009, 58 (2), 145-157.

Rutkowski, Gregory K, Charles L Gruder, and Daniel Romer, "Group cohesiveness, social norms, and bystander intervention.," Journal of Personality and Social Psychology, 1983, 44 (3), 545.

Shachat, Jason M, "Mixed strategy play and the minimax hypothesis," Journal of Economic Theory, 2002, 104 (1), 189-226.

Weesie, Jeroen, "Incomplete Information and Timing in the Volunteer's Dilemma A Comparison of Four Models," Journal of Conflict Resolution, 1994, $38(3), 557-585$. 


\section{A Appendix}

\section{A.1 Proofs}

\section{Proposition 1}

Recall the structure of the game, where $b>c$.

\begin{tabular}{r|ccccc} 
& \multicolumn{4}{c}{ Number of other cooperators } \\
own choice & 0 & 1 & 2 & $\ldots$ & $\mathrm{N}-1$ \\
\hline cooperate & $b-c$ & $b-c$ & $b-c$ & $\ldots$ & $b-c$ \\
defect & 0 & $b$ & $b$ & $\ldots$ & $b$
\end{tabular}

We define $x_{i}$ as the action of player $i$ with $i \in\{C, D\}$. We assume that the number of players $N$ is a random variable with support on $\{1, \ldots, \bar{N}\}$ where $\bar{N}$ is some fixed maximum number of players.

Proposition 1 (Volunteering under population uncertainty):

In the Volunteer's Dilemma, given fixed benefits and costs and given two distributions of the population size, $f$ and $g$, and let $f$ be a mean-preserving spread of $g$. The MSNE probability to cooperate is (weakly) higher under $f$ compared to $g$.

To prove the theorem, we will compare the optimal choice under two probability functions $f$ and $g$ with $f \neq g$, where the random value $N$ can take $\bar{N}$ possible values, with $n \in \tilde{N}=\{1, \ldots, \bar{N}\}$, where $f(n)$ is the probability of $N$ taking the value $n$ under distribution $f(g(n)$ is defined accordingly). Further, we assume that $f$ is a mean-preserving spread of $g\left(f_{m p s} g\right)$.

Given that all other players play the symmetric mixed Nash equilibrium strategy $p^{*}$ (where $p$ is the probability to cooperate) every player in the game must be indifferent between cooperation and defection in order to establish the Nash equilibrium.

$$
\begin{aligned}
U(C) & =U(D) \\
b-c & =b \operatorname{Prob}\left(X_{-i}>0\right)=b\left(1-\operatorname{Prob}\left(X_{-i}=0\right)\right)
\end{aligned}
$$

where $X_{-i}$ is the number of other cooperators. This reduces to the following equation:

$$
\frac{c}{b}=\operatorname{Prob}\left(X_{-i}=0\right) .
$$

Let

$$
\operatorname{Prob}\left(X_{-i}=0\right)=P_{h}=\sum_{n \in \tilde{N}} h(n)(1-p)^{n-1},
$$

where $h$ represents the corresponding distribution function ( $f$ or $g$ in our case) and $P_{h}$ defines the probability to cooperate under that distribution function. Now we compare the right-hand side of equation (6) under the two distribution functions.

We need to show that: 


$$
P_{f}=\sum_{n \in \tilde{N}} f(n)(1-p)^{n-1}>\sum_{n \in \tilde{N}} g(n)(1-p)^{n-1}=P_{g} .
$$

Note that $(1-p)^{n-1}$ is convex and decreasing in $n$ (for $p<1$ ). From $f_{m p s} g$ it follows that $g$ second order stochastically dominates $f$ and thus: $\sum_{n \in \tilde{N}} f(n) u(n) \leq$ $\sum_{n \in \tilde{N}} g(n) u(n)$ for every concave function $u(n)$. Conversely we get $\sum_{n \in \tilde{N}} g(n) c(n)<$ $\sum_{n \in \tilde{N}} f(n) c(n)$ for any convex function $c(n)=-u(n)$. If we set $c(n):=$ $(1-p)^{n-1}$ we get the above inequation (7):

$$
P_{f}>P_{g} \text {. }
$$

The following graph helps to visualize the last step of the proof.

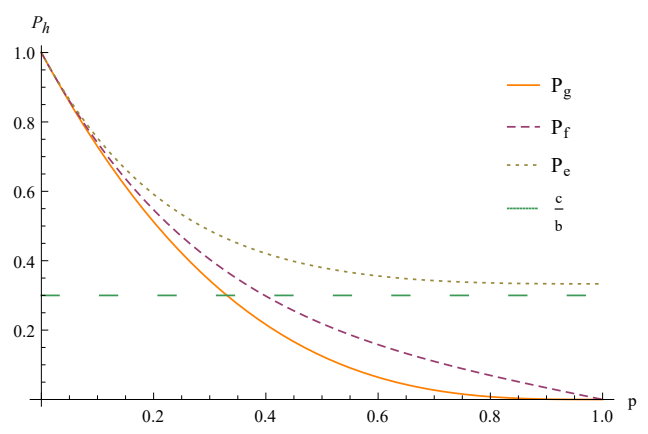

Figure 4: $\operatorname{Prob}\left(X_{-i}=0\right)$ dependent on $p$ for some distribution functions $f, g, e$ with $f(1)=g(1)=0$ and $e(1)>0$

Note that $\frac{\delta P_{h}}{\delta p}<0$. Now let $p_{h}^{*}$ be the mixed strategy Nash equilibrium under probability distribution $h$, solving equation (5) (under the condition that $\left.p^{*} \in[0,1]\right)$. Thus, from condition (5) it follows directly that $p_{f}^{*} \geq p_{g}^{*}$. The equal sign holds for cases where $\frac{c}{b}$ is small and $g(1)>0$ and $f(1)>0$ s.t. $p_{g}^{*}=1=p_{f}^{*}$ (compare $P_{e}$ in the above graph). q.e.d.

\section{Proposition 2}

Let $p_{h}^{*}\left(\frac{c}{b}\right)$ be the MSNE cooperation rate under distribution $h$ when the costbenefit ratio is equal to $\frac{c}{b}$.

Proposition 2 Incentives and population uncertainty): In the Volunteer's Dilemma, given two distributions of the population, $f$ and $g$ : If $f$ is a mean-preserving spread of $g$ and $f(1)>\frac{c}{b}$ then there exists some $\left(\frac{\hat{c}}{b}\right)$ s.t. the difference $p_{f}^{*}\left(\frac{c}{b}\right)-p_{g}^{*}\left(\frac{c}{b}\right)$ is decreasing in $\frac{c}{b}$ for $\frac{c}{b}>\left(\frac{\hat{c}}{b}\right)$ and increasing in $\frac{c}{b}$ for $\frac{c}{b}<\left(\frac{\hat{c}}{b}\right)$.

Let us write $P_{h}=P_{h}(p)$ to show the connection between $P_{h}$ and $p$ for a given distribution $h$. First, note that $P_{h}(0)=1$ and $P_{h}(1)=h(1)$ (the probability of being alone), as can be seen in figure (4). Further, $P_{h}(p)$ is decreasing and convex in $p$. Taking the result above, we know that $P_{f} \geq P_{g}$ if $f_{m p s} g$. It is thus easy to see that there is some $\left(\frac{\hat{c}}{b}\right)$ where $\Delta\left(f, g, \frac{c}{b}\right)=p_{f}^{*}\left(\frac{c}{b}\right)-p_{g}^{*}\left(\frac{c}{b}\right)$ is maximal and $p_{f}^{*}\left(\left(\frac{\hat{c}}{b}\right)\right)<1$ s.t. the difference is decreasing for $\frac{c}{b}>\left(\frac{\hat{c}}{b}\right)$ and increasing 
for $\frac{c}{b}<\left(\frac{\hat{c}}{b}\right)$. Note that, if $f(1)>0$, then $\Delta\left(f, g, \frac{c}{b}\right)$ is largest at $f(1)$, that is, $\Delta\left(f, g, \frac{c}{b}\right)$ is decreasing in $\frac{c}{b}$. q.e.d.

\section{Criticality}

We model pessimism as first-order dominance. That is, the pessimistic distribution function (denote this by $f_{p}$ ) of the group size is first-order stochastically dominated by the actual distribution function $\left(f_{a}\right)$. It follows that for any value of $p$ (the cooperation rate of all others), the perceived criticality, i.e., the probability that no one else is cooperating, is higher under the pessimistic distribution function (Hypothesis 4).

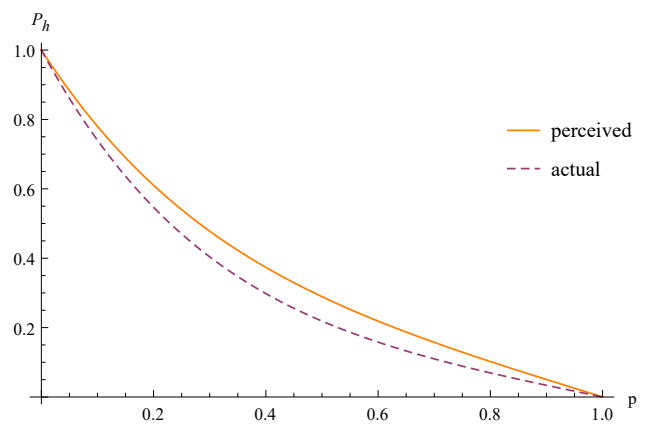

Figure 5: $\operatorname{Prob}\left(X_{-i}=0\right)$ dependent on $p$ for an actual and biased distribution function

Since $f_{a}$ first-order stochastically dominates $f_{p}, f_{p}$ is also second-order stochastically dominated by $f_{a}$. Thus, similar to the proof of proposition 1 it follows that the symmetric MSNE rate of cooperation is higher under pessimistic beliefs (Hypothesis 5). 


\section{A.2 Questionnaire}

Volunteering was framed as contributing to a project. The following questionnaire was administered at the end of the experiment.

We use a principal factor model with oblimin rotation. We retain two factors following Osborne and Costello (2009). The results presented in this paper are qualitatively the same for alternative methods of the factor analysis. Also, note that item 8 cannot be clearly captured by the two factors. Including this item separately in the regression or retaining more factors does not change the result and the coefficient is positive and significant for that item. 


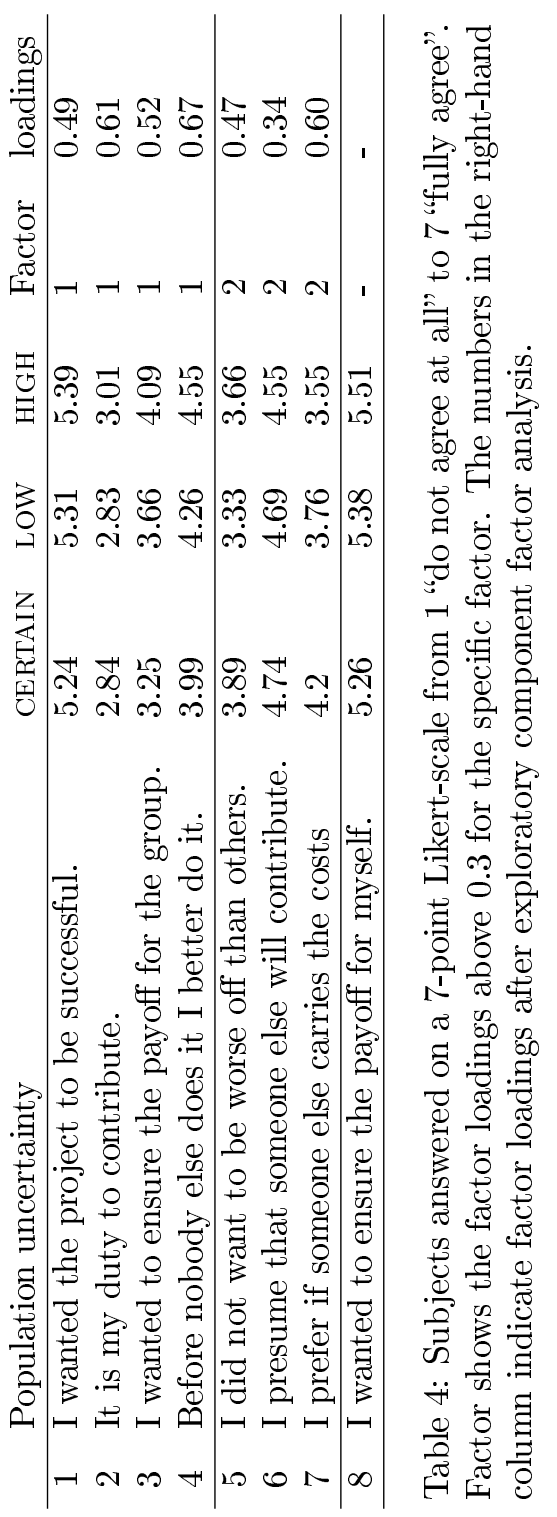




\section{A.3 Further statistical analysis}

\section{A.3.1 Nash Predictions}

\begin{tabular}{lccc} 
& observed $(\hat{\mu} /$ s.e. $)$ & predicted & $p$ (two-sided t-test) \\
\hline low costs & $.42 / .042$ & .36 & .15 \\
CERTAIN & $.52 / .046$ & .39 & $<.01$ \\
LOW UNCERTAINTY & $.63 / .042$ & .58 & .22 \\
HIGH UNCERTAINTY & & & \\
high costs & $.41 / .046$ & .29 & $<.05$ \\
CERTAIN & $.53 / .044$ & .31 & $<.0001$ \\
LOW UNCERTAINTY & $.58 / .039$ & .39 & $<.0001$ \\
HIGH UNCERTAINTY & .59 & \\
\hline
\end{tabular}

Table 5: Comparing the volunteering rate predicted by the mixed Nash equilibrium to observed choices with a two-sided t-test. 


\section{A.3.2 Criticality}

The following analyses provide further evidence on the differences in perceived and objective criticality accross treatments.

\begin{tabular}{lcc} 
& LOW UNCERTAINTY & HIGH UNCERTAINTY \\
\hline low cost & .9984 & .325 \\
CERTAIN $(.43)$ & & .5107 \\
LOW UNCERTAINTY $(.43)$ & & \\
HIGH UNCERTAINTY $(.45)$ & & \\
high cost & .0546 & .0728 \\
CERTAIN $(.48)$ & & .7959 \\
LOW UNCERTAINTY $(.41)$ & & \\
HIGH UNCERTAINTY $(.41)$ & & \\
\hline
\end{tabular}

Table 6: T-test of the treatment differences in perceived criticality. The values in the cells display p-values for the test between the row and the column (e.g., CERTAIN vs. LOW UNCERTAINTY in the low-cost condition, $\mathrm{p}=.9984$ ). The values in parenthesis display the average level of perceived criticality.

\begin{tabular}{lccc} 
& actual $(\hat{\mu} /$ s.e. $)$ & perceived $(\hat{\mu} /$ s.e. $)$ & $p$ (two-sided test of proportions) \\
\hline CERTAIN & $.45 / .042$ & $.34 / .04$ & .049 \\
LOW UNCERTAINTY & $.42 / .041$ & $.26 / .04$ & $<.01$ \\
HIGH UNCERTAINTY & $.43 / .041$ & $.39 / 04$ & .48
\end{tabular}

Table 7: Comparing perceived to actual criticality with a test of proportions. The actual criticality is calculated as $\frac{1}{3} \sum_{r=1}^{3}\left(1-\left(1-\hat{v}^{t}\right)^{N_{r}-1}\right)$, where $\hat{v}^{t}$ is the average probability to volunteer in treatment $t$, and $N_{r}$ is the potential number of players (e.g., 2, 3, and 4 in LOW UNCERTAINTY)

\section{A.3.3 Appropriate contribution}

LOW UNCERTAINTY HIGH UNCERTAINTY

\begin{tabular}{lcc}
\hline low cost & .6184 & .8298 \\
CERTAIN $(0.58)$ & & .4889 \\
LOW UNCERTAINTY (0.60) & & \\
HIGH UNCERTAINTY (0.57) & & \\
high cost & .0174 & .0019 \\
CERTAIN (0.50) & & .3294 \\
LOW UNCERTAINTY (0.60) & & \\
HIGH UNCERTAINTY (0.64) &
\end{tabular}

Table 8: T-test (two-sided) of the treatment differences in appropriate contribution. The values in the cells display $\mathrm{p}$-values for the test between the row and the column (e.g., CERTAIN vs. LOW UNCERTAINTY in the low-cost condition, $p$ $=.6184)$. The values in parenthesis display the average level. 


\section{A.3.4 Beliefs}
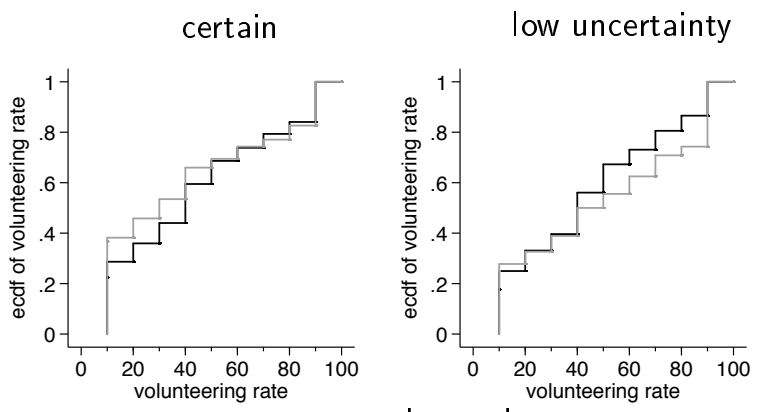

high uncertainty

observed

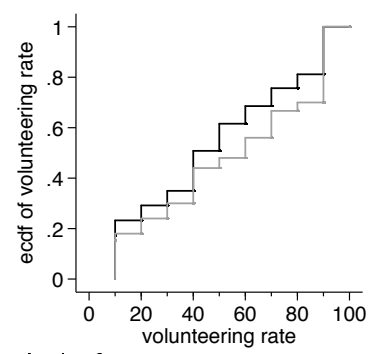

beliefs
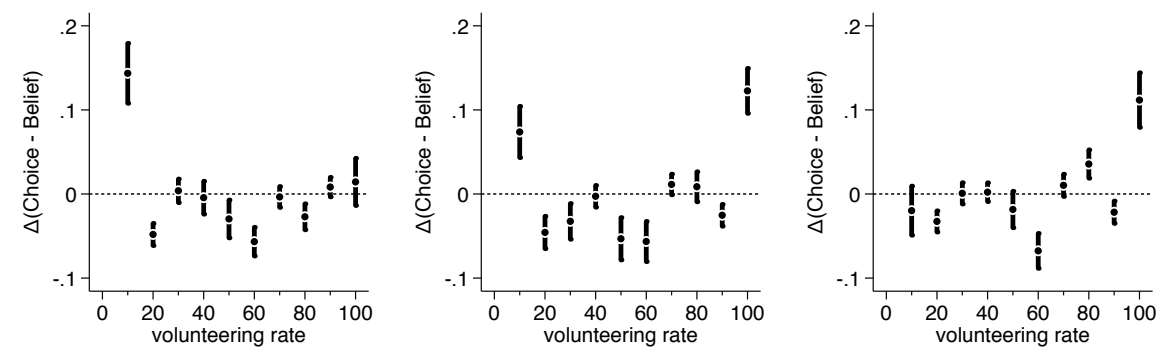

Figure 6: ECDF for first-order action beliefs compared observed choices (top) and differences between the average beliefs and the observed choices (bottom). Error bars in the bottom panel display $95 \%$ confidence intervals. The data for the empirical volunteering rate was binned to intervals of $10 \%$. The data for the beliefs was elicited in bins of $10 \%$. 


\section{A.3.5 Additional regression results}

Table 9: Fractional logit regression estimating the probability to volunteer.

\begin{tabular}{|c|c|c|c|c|c|c|}
\hline & (1) & (2) & (3) & (4) & (5) & (6) \\
\hline LOW UNCERTAINTY & $\begin{array}{c}0.118^{* *} \\
(2.65)\end{array}$ & $\begin{array}{c}0.107^{+} \\
(1.71)\end{array}$ & $\begin{array}{l}0.101^{*} \\
(2.09)\end{array}$ & $\begin{array}{r}0.0998^{*} \\
(2.11)\end{array}$ & $\begin{array}{c}0.0942^{*} \\
(2.11)\end{array}$ & $\begin{array}{c}0.0865^{*} \\
(1.98)\end{array}$ \\
\hline HIGH UNCERTAINTY & $\begin{array}{l}0.193^{* * *} \\
(4.53)\end{array}$ & $\begin{array}{l}0.210^{* * *} \\
(3.53)\end{array}$ & $\begin{array}{c}0.139^{* *} \\
(3.07)\end{array}$ & $\begin{array}{c}0.133^{* *} \\
(2.99)\end{array}$ & $\begin{array}{c}0.145^{* * *} \\
(3.48)\end{array}$ & $\begin{array}{c}0.134^{* *} \\
(3.27)\end{array}$ \\
\hline high costs & $\begin{array}{c}-0.0190 \\
(-0.54)\end{array}$ & $\begin{array}{c}-0.0143 \\
(-0.23)\end{array}$ & $\begin{array}{l}0.0622 \\
(1.29)\end{array}$ & $\begin{array}{l}0.0635 \\
(1.31)\end{array}$ & $\begin{array}{c}0.0764^{+} \\
(1.72)\end{array}$ & $\begin{array}{l}0.0673 \\
(1.54)\end{array}$ \\
\hline $\begin{array}{l}\text { LOW UNCERTAINTY } \times \\
\text { high costs }\end{array}$ & & $\begin{array}{c}0.0219 \\
(0.25)\end{array}$ & $\begin{array}{l}-0.0842 \\
(-1.26)\end{array}$ & $\begin{array}{l}-0.0849 \\
(-1.28)\end{array}$ & $\begin{array}{c}-0.0932 \\
(-1.47)\end{array}$ & $\begin{array}{c}-0.0689 \\
(-1.12)\end{array}$ \\
\hline $\begin{array}{l}\text { HIGH UNCERTAINTY } \times \\
\text { high costs }\end{array}$ & & $\begin{array}{c}-0.0360 \\
(-0.42)\end{array}$ & $\begin{array}{l}-0.0899 \\
(-1.45)\end{array}$ & $\begin{array}{l}-0.100 \\
(-1.64)\end{array}$ & $\begin{array}{l}-0.122^{*} \\
(-2.09)\end{array}$ & $\begin{array}{l}-0.104^{+} \\
(-1.78)\end{array}$ \\
\hline subj. criticality & & & $\begin{array}{c}-0.00229^{* * *} \\
(-3.86)\end{array}$ & $\begin{array}{c}-0.00154^{*} \\
(-2.41)\end{array}$ & $\begin{array}{c}-0.00143^{*} \\
(-2.35)\end{array}$ & $\begin{array}{c}-0.00136^{*} \\
(-2.26)\end{array}$ \\
\hline pro-social & & & $\begin{array}{c}0.203^{* * *} \\
(11.20)\end{array}$ & $\begin{array}{c}0.192^{* * *} \\
(10.63)\end{array}$ & $\begin{array}{l}0.174^{* * *} \\
(9.62)\end{array}$ & $\begin{array}{l}0.171^{* * *} \\
(8.97)\end{array}$ \\
\hline pro-self & & & $\begin{array}{c}-0.113^{* * *} \\
(-5.39)\end{array}$ & $\begin{array}{c}-0.113^{* * *} \\
(-5.63)\end{array}$ & $\begin{array}{c}-0.110^{* * *} \\
(-5.70)\end{array}$ & $\begin{array}{c}-0.110^{* * *} \\
(-5.87)\end{array}$ \\
\hline 1st-order beliefs & & & & $\begin{array}{c}0.00289^{*} \\
(2.51)\end{array}$ & $\begin{array}{c}0.00133 \\
(1.20)\end{array}$ & $\begin{array}{c}0.00121 \\
(1.10)\end{array}$ \\
\hline appropriate & & & & & $\begin{array}{c}0.00273^{* * *} \\
(4.88)\end{array}$ & $\begin{array}{c}0.00273^{* * *} \\
\quad(5.09)\end{array}$ \\
\hline risk-seeking & & & & & & $\begin{array}{c}0.00106 \\
(1.01)\end{array}$ \\
\hline Controls & & & & & & yes \\
\hline Observations & 438 & 438 & 438 & 438 & 438 & 438 \\
\hline Pseudo $R^{2}$ & 0.019 & 0.019 & 0.238 & 0.245 & 0.264 & 0.273 \\
\hline
\end{tabular}

$z$ statistics in parentheses

$+p<.10,^{*} p<.05,{ }^{* *} p<.01,{ }^{* * *} p<.001$

Note Estimates show average marginal effects. LOW UNCERTAINTY and HIGH UNCERTAINTY are dummyvariables indicating the corresponding uncertainty conditions. HIGH COSTS is a dummy taking " 1 " for the conditions with a high cost-benefit ratio. Perceived criticality stems from our measure of criticality and takes values from 0 to 100 . Belief is the average belief in the belief task, taking values between 0 and 100 . Risk is the number of boxes in the BRET risk task. More boxes indicate higher risk tolerance. Pro-social and Pro-self are the two factors obtained from the exploratory factor analysis. Appropriate states the normative belief (0-100). Controls entails age, gender and field of study. 


\section{A.3.6 Belief measure}

The picture shows a screenshot of the original belief task as faced by subjects. Subjects are asked to decide how many of 100 other participants would select a choice (number of blue balls out of 100 in the urn) in the corresponding bins. The bars thus had to add up to 100 .

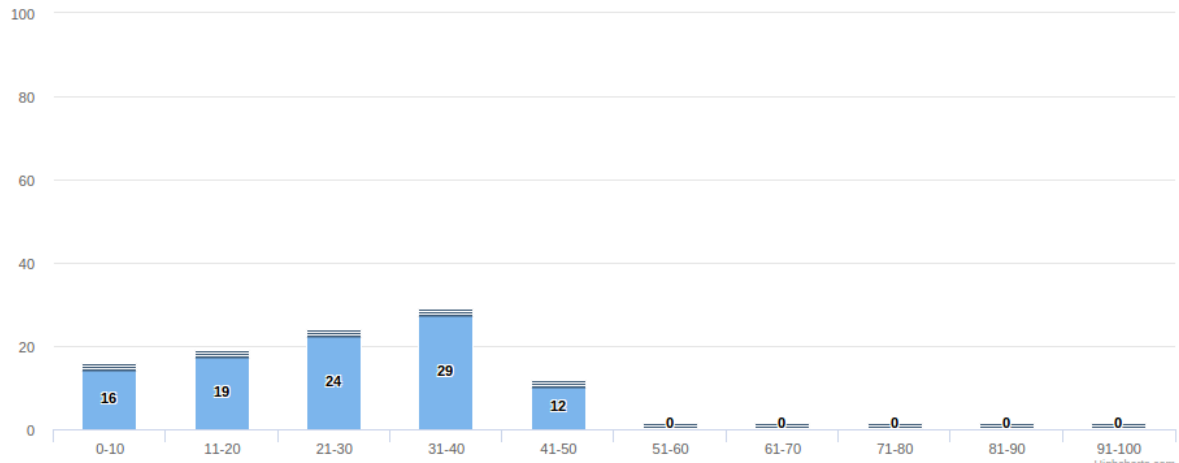

Figure 7: Belief elicitation task. 


\section{A.4 Instructions}

These are the instructions for the CERTAIN treatment with low costs. The differences to the other treatments are marked in brackets.

\section{Instructions}

In this experiment, you will work with a random number of other participants on a project. You will learn the number of participants later on. Every participant decides for himself about whether he wants to contribute to the project or not. All participants make this decision simultaneously and without knowing the decision of the other participants.

The project counts as successful if at least one of the participants contributes to the project. In this case, each participant receives 10 €independent of whether they contributed themselves to the project or not. Contributions of more than one person do not increase the amount of $10 €$.

Every participant contributing to the project carries cost of $5 €[4 €]$ independent of the number of other participants who contribute. Contributing participants are deducted costs of $5 €[4 €]$ of their $10 €$ such that they receive $10 €-5 €[4 €]=5 €[6 €]$.

If no participant contributes to the project, all participants receive a payoff of $0 €$.

See the following overview of your possible payments.

\begin{tabular}{|lcc|}
\hline If you did contribute & $10 €-5 €[4 €]=5 €[6 €]$ & \\
If you did not contribute & $10 €$ & if someone else contributed \\
& $0 €$ & if no one else contributed \\
\hline
\end{tabular}

These payments are the same for all other participants.

Later the computer will decide about the actual number of participants.

The number of other participants who can also contribute to the project will be randomly determined by the computer. [ With equal probability you will be working together with one, two or three [no one, two, or four] particpants. That is, in total 2, 3, or $4[1,3$, or 5] participants will work on the project.]

You will learn the number of other participants on the screen before making your decision. [The number of other participants will be revealed on the screen after you make your decision].

Thus, when making your decision, you know the number, but not the decisions of the other participants. [Thus, when making your decision, you know neither the number, nor the decisions of the other participants.] These instructions will also be visible on the decision screen.

Your decision will be made with the help of a virtual urn. You can fill this urn with a total of 100 green or blue balls. Here the blue balls stand for contributing and the green balls for non-contributing.

After you have determined the number of blue and green balls in the urn the computer will randomly draw one ball from the urn. That ball then determines your choice. Thus, if you want to contribute for sure, just put 100 blue balls in the urn. If you do not want to contribute at all, put 100 green balls in the urn. If you want to contribute with probability $\mathrm{X} \%$, just put $\mathrm{X}$ blue balls in the urn. All other participants make their decisions in the same way, each with his own urn, from which one ball will then be drawn. 